\title{
Prevalence of cigarette smoking in developing countries
}

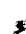

,

's

$*$
The World Health Organisation (WHO) estimates that about $50 \%$ of men and $8 \%$ of women in developing countries are smokers. About 800 million of the world's estimated 1.1 billion smokers $(73 \%$ of the total) are in developing countries. Ganiwijaya $e t a l^{1}$ are correct when they assert in this issue of Tobacco Control that "High rates of cigarette smoking observed among males in Indonesia are likely to be associated with future substantial morbidity and mortality unless current smoking trends can be reversed." It is precisely these high rates of current smoking, prevalent not only in West Java, but throughout the developing world, that have led to the appalling prediction by epidemiologists that the number of deaths caused by smoking in developing countries will grow from approximately one million per year in the 1990 s to seven million per year in the 2020 s or 2030 s.

Ganiwijaya $e t a l^{1}$ report a male smoking prevalence of $84 \%$ among men and $5 \%$ among women in six rural villages of West Java. Are these results plausible? Rates for women are similar to those observed in other prevalence surveys conducted in Indonesia and other neighbouring countries. Estimated national smoking prevalence rates for men in China, Indonesia, Japan, the Philippines, and the Republic of Korea, all range from $60 \%$ to $70 \%$. Given these high smoking prevalence rates for several populous countries in the region, it is certainly plausible that prevalence could be as high as $84 \%$ for some subpopulations, such as six rural villages in West Java.

Exact comparisons of results from different surveys in the region are fraught with difficulty, mainly because of the lack of standardisation in smoking survey questions and methods. That is why the WHO has actively promoted the use of standardised core questions and methodology for determining smoking status. ${ }^{3,4} \mathrm{~A}$ revised version of WHO's recommended core questions has been completed recently and will facilitate the national, regional, and global surveillance of trends in and patterns of tobacco use.

Regrettably, the survey questions used by Ganiwijaya $e t$ $a l^{1}$ deviate somewhat from WHO recommendations. For example, the questions asked in their survey yield information on the total number of current (daily plus occasional) smokers, but do not allow differentiation between daily and occasional smokers, as recommended by WHO. Because other surveys frequently report only daily smoking, it is difficult to compare these findings with other survey results for Indonesia and neighbouring countries. Certainly, the very broad definition of current smokers used in this study would probably cover all non-daily smokers. This might conceivably be as high as $10 \%$ of those reported as current smokers, which would bring the estimated prevalence reported in the study much closer to previous estimates.

While the particular definitions chosen for this study are likely to have led to an overestimation of prevalence among men, Ganiwijaya $e t a l^{1}$ were able to include the smoking questions on a complete household census of the six villages under study, thereby minimising sampling error. Certainly, there is an impressive consistency in the age pattern of prevalence for both sexes. Moreover, the study suggests that the strong social class gradient in smoking behaviour characteristic of developed countries is now apparent in Indonesian men as well. This may be preliminary evidence that messages and information about the health hazards of smoking are reaching the better educated and well off sectors of the population, although their prevalence rates of $60 \%$ or so are very much higher than what is observed among men of comparable social class in industrialised countries.

Another significant aspect of this study in the confirmation that prevalence rates are very low (typically about $5 \%$ ) among Indonesian women. While there does not appear to be a marked age pattern of prevalence, smoking rates among women in the high income bracket are reported to be almost twice as high as those among lower income workers. This is a disturbing finding, which suggests that better off women are already beginning to smoke in significant numbers. The claim by the authors that Indonesian women represent a large target population for effective primary prevention approaches, while broadly true, is likely to be increasingly challenged by the rapid modernisation and industrialisation taking place in the archipelago. Tobacco control advocates must realise that effective primary prevention is required for women, now, just as much as it is for men.

The paper by Ganiwijaya $e t$ al is important because it provides recent confirmation of the very high smoking prevalence rates in large male populations in Southern and Eastern Asia. Whether prevalence is $84 \%$ or $60 \%$, as suggested by another survey reported in the paper, is largely irrelevant for public health policy. If about two out of three Indonesian men are smokers, and if, as current evidence suggests, half might eventually die from tobacco, then the future death toll from tobacco will be very substantial indeed. This prospect alone should be sufficient to help spur national governments to implement comprehensive tobacco control policies and programmes, also strongly recommended by WHO. ${ }^{5,6}$ Such action is needed urgently if there is to be any mitigation of the looming epidemic in developing countries of seven million deaths per year caused by tobacco, the majority of which are likely to occur in Indonesia and other countries of the region.

NEIL E COLLISHAW ALAN D LOPEZ

Programme on Substance Abuse World Health Organisation

CH-1211 Geneva 27

Switzerland

1 Ganiwijaya T, Sjukrudin E, De Backer G, Suhana D, Brotoprawiro S, Sukandar $\mathrm{H}$. Prevalence of cigarette smoking in a rural area of West Java, Indonesia. Tobacco Control 1995; $4: 335-7$.

2 Peto $\mathrm{R}$, Lopez AD, Boreham J, Thun $\mathrm{M}$, Heath $\mathrm{C}$. Mortality from smoking in developed countries 1950-2000: indirect estimates from national vital in developed countries 1950-2000: indirect estimates
statistics. Oxford: Oxford University Press, 1994.

3 Guidelines for the conduct of tobacco smoking surveys of the general population. Report of a WHO meeting held in Helsinki, Finland, 19 November -4
Reporing Report of a WHO meeting held in Helsinki, Finland, 19 November -
December 1982. Geneva: World Health Organisation, 1983. (Document December 1982. Gen
WHO/SMO/83.4.)

4 The evaluation and monitoring of public action on tobacco. Smoke-free Europe : 3. Copenhagen: World Health Organisation (Regional Office for Europe) and the Commission of the European Communities, 1987.

5 Tobacco or health. In: Handbook of resolutions and decisions of the World Health Assembly and the Executive Board, vol III, $1 \mathrm{st}$ ed. (WHA3914/1986.) Geneva: World Health Organisation, 1986: 15-16.

6 Tobacco or health. In: Forty-third World Health Assembly, resolutions and decisions: annexes. (WHA43/1990/REC/1.) Assembly, resolutions and Organisation, 1990: 15-16. 